\title{
Simulation of hydration and cracking propagation with temperature effect based on fuzzy logic theory
}

\author{
P. Štemberk*, A. Rainová** \\ *Czech Technical University in Prague, Thákurova 7, 16629 Prague, Czech Republic, E-mail: stemberk@fsv.cvut.cz \\ **Czech Technical University in Prague, Thákurova 7, 16629 Prague, Czech Republic, \\ E-mail: aneta.rainova@fsv.cvut.cz
}

crossref http://dx.doi.org/10.5755/j01.mech.17.4.561

\section{Introduction}

Hydration heat is one of the most important factors which are considered during execution of concrete structures. Especially in the case of massive structures, the hydration heat introduces a risk for the future performance of concrete structure as the nonuniform shrinkage during cooling of the structure can result in cracking.

When performing numerical analyses, e.g. by using the finite element method, the knowledge of the rate of the hydration reaction at each time step is necessary. The construction standards provide some basic hydration curve, which in most cases describes the cumulative hydration heat in dependence on age of concrete, nevertheless, the values of such hydration curves are obtained only for the adiabatic or isothermal conditions. Therefore, if such hydration curves are used in the numerical analysis, the effect of temperature on the hydration reaction is not considered at all, which results in unrealistic temperature distribution and its evolution over time. The use of such hydration curves is unacceptable, for example, in numerical analyses when the optimum scheduling of concrete casting with respect to daily temperature is the desired result

The proposed simulation of hydration heat liberation is programmed in Matlab environment using fuzzylogic finite element tools. The possible risk of cracking due to shrinkage and thermal volumetric changes is also considered.

\section{Hydration of concrete}

At the time of the global economic crisis, the topic of saving money is more important than ever. When it is possible to predict the evolution of mechanical properties of materials more accurate, then the technological breaks on construction sites can be reduced, thus the cost would be reduced. For estimation of the mechanical properties of early age concrete, the concept of the degree of hydration was adopted [1]. The degree of hydration can be defined as the ratio between the actual amount of released heat and the total amount of disposable heat, which can be liberated by the hydration reaction, or the ratio between the already spent and the total amount of cement particles, which are disposable for the reaction. The value of the degree of hydration varies within the interval $<0,1>$, when 0 means beginning of the reaction and 1 symbolizes completion of the reaction. It was proved that the instantaneous strength of concrete can be derived directly from the value of the degree of hydration, which is important especially for the early age concrete, when the range of experimental destructive methods is limited. Fig. 1 shows the typical shape of the hydration curve of concrete given by standards. Usually, the standards neglect the initial nonlinear increase of the curve.

The hydration curve expresses the dependences on cement composition and on fineness of grading, on water-cement ratio, relative humidity, on the amount of contained gypsum, and on temperature [2], which is the main objective of this paper. Temperature influences mainly the rate of reaction at the acceleration stage of the reaction, and also the maximum possible hydration degree, which can be attained with respect to the temperature conditions and the previous reaction progress. High temperatures accelerate the hydration reaction. This is because the higher temperature at the beginning of the reaction is followed by

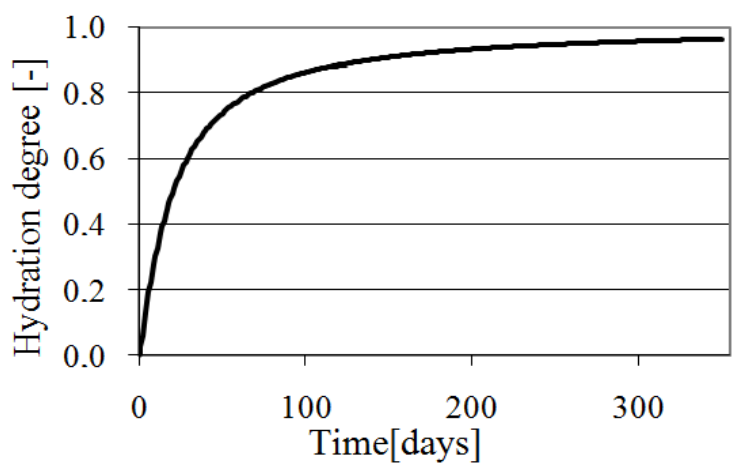

Fig. 1 Typical hydration reaction curve

more rapid growth of the hydration products, which in turn means enclosing of free cement particles inside the hydrated layers of the hydration products formed on the surface of the larger cement clusters. It also follows that water permeation is no longer controlled by the kinetic energy, but it depends on diffusion of water through the hydrated cement layers. Rapid early increase of the hydration degree later retards water permeation to the unhydrated cement particles, which results in deceleration of the hydration reaction and it may also result in not reaching the maximum value of the degree of hydration. It was also proved that time the hydration reaction can be divided into two main parts [2]. In the first part, the hydration reaction is controlled by the kinetic energy and the hydration reaction rate depends directly on temperature. In the latter part, the reaction is controlled by diffusion with no clear dependence on the actual temperature, but the temperature history should be considered instead. This differentiation in the controlling mechanism of the hydration reaction is shown in Fig. 2, which contains experimental data on activation energy with respect to various constant temperatures obtained in isothermal calorimetry tests [2]. The border be- 
tween the parts can be clearly distinguished at about $50 \%$ of the degree of hydration.

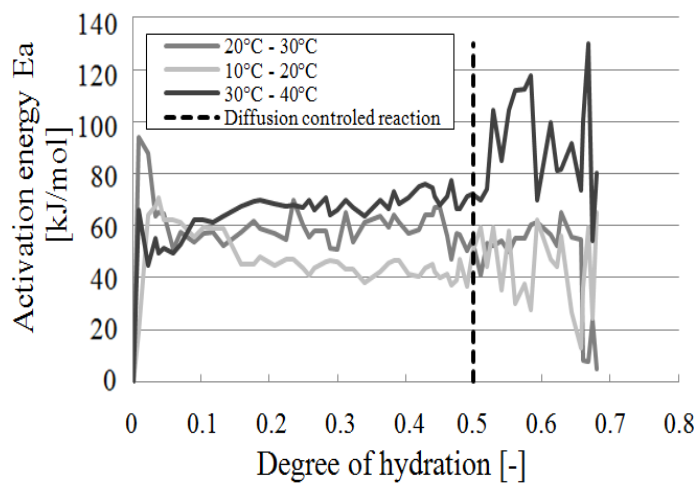

Fig. 2 Relationship between activation energy and degree of hydration [2]

Two basic approaches are used for experimental investigation of heat liberation from hydration reaction: isothermal calorimetry and adiabatic calorimetry. In the adiabatic calorimetry, the entire system is insulated so that there is no heat exchange with the ambient environment. The heat from the hydration reaction remains cumulated inside the body and the reaction accelerated by the increasing temperature. On the contrary, in the isothermal calorimetry, the temperature of the body is kept constant and the additional heat removed or added into the body, therefore, the hydration reaction is artificially either decelerated or accelerated, respectively. However, under the realistic conditions, temperature varies between these two limit conditions. In the following analyses, the realistic distribution of ambient temperature simulated using the sine function, when the seasonal effects are covered by the mean value of the sine and the daily cycles are defined by the amplitude of the sine function.

The fuzzy-logic model for description of the dependence of the rate of hydration reaction on temperate is based on the experimental data measured in an isothermal calorimetry test [2]. The curves showing the rate of hydration reaction at constant temperatures for the initial 40 hours, which are considered in the modelling, are shown in Fig. 3.

\section{General description of algorithm}

The simulation algorithm was developed in Matlab environment and it is intended for simulation of hydration of concrete with the assessment of possible cracking. The algorithm consists of three basic routines.

The first routine is the thermal analysis based on the finite element method. The second routine is on the fuzzy logic principles and it evaluates the rate of hydration at each time step, for which is utilizes the experimental data obtained from the isothermal calorimetry.

The resulting rate of hydration is then used by the first routine in the form of the heat source, which occurs in the right-hand side of the governing equation for the thermal analysis. The third routine evaluates the possible cracking due to shrinkage and thermal expansion and subsequent contraction. The shrinkage model is based on the commonly accepted B3 model [3]. In this routine, the stress caused by thermal expansion and contraction and the shrinkage across a cross-section is compared with the in-

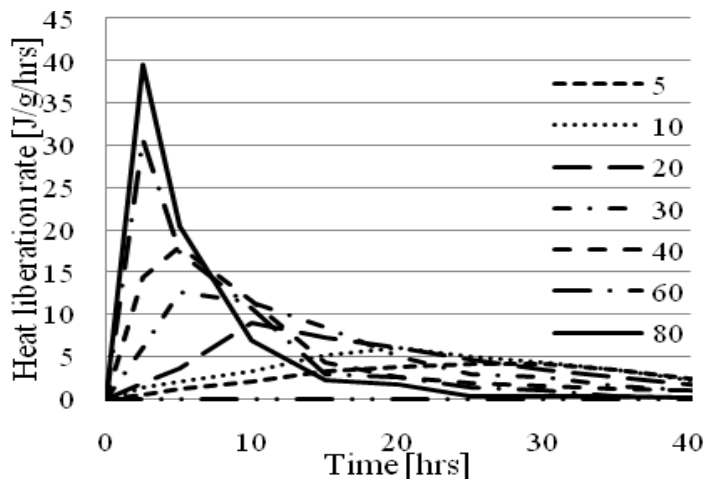

Fig. 3 Hydration rates for different temperatures

stantaneous tensile strength of concrete and in the case of the stresses exceed the tensile strength, the depth of the crack [4] is assessed.

\section{First routine - finite element thermal analysis}

Within the scope of this paper, a two-dimensional thermal-analysis problem is considered. Fig. 4 shows the representative cross-section in a massive concrete wall. Due to the geometry of the cross-section of the wall, the principal direction where the heat losses are prominent are along the thickness direction of the wall, $L_{z}$. The Dirichlettype boundary conditions are indicated in Fig. 4 and they

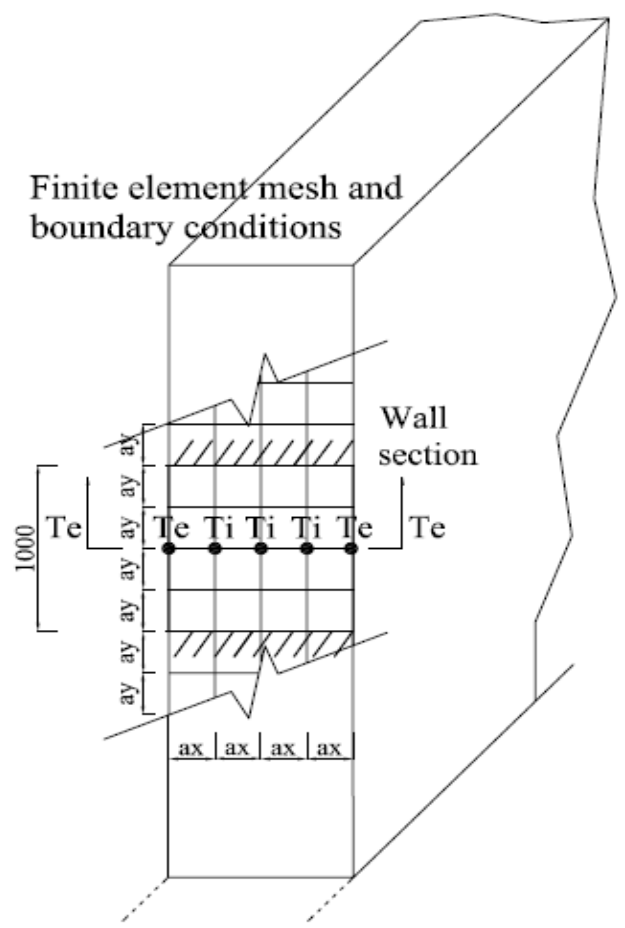

Fig. 4 Geometry of analyzed cross-section

are considered acceptable for the illustrative purposes of this paper. The finite elements used in the thermal analysis are the bi-linear isoparametric quadrilateral elements. The temperatures at the surfaces of the wall are described according to the ambient temperature history, which means that the nodal prescribed temperatures are updated at each time step. The heat sources in the form of the hydration rate are obtained from the second routine and the thermal parameters of concrete are considered constant. 


\section{Second routine - fuzzy-logic model of hydration heat liberation}

The fuzzy set theory deals with the definitions of inexplicit or verbally expressed phenomena and it is relatively new approach for solving the problems, where it is necessary to assign mathematical values to verbally expressed rules, which are interpolated by using the membership functions of the input fuzzy sets, or where is necessary to input expert opinions into a controlling or simulation system. The advantage of this approach is also in the processing of experimental data, which may be incomplete for some areas. Then the fuzzy logic decision-making is applied. This approach is used in application in many industrial fields [5]. More on fuzzy logic can be found in $[6,7]$.

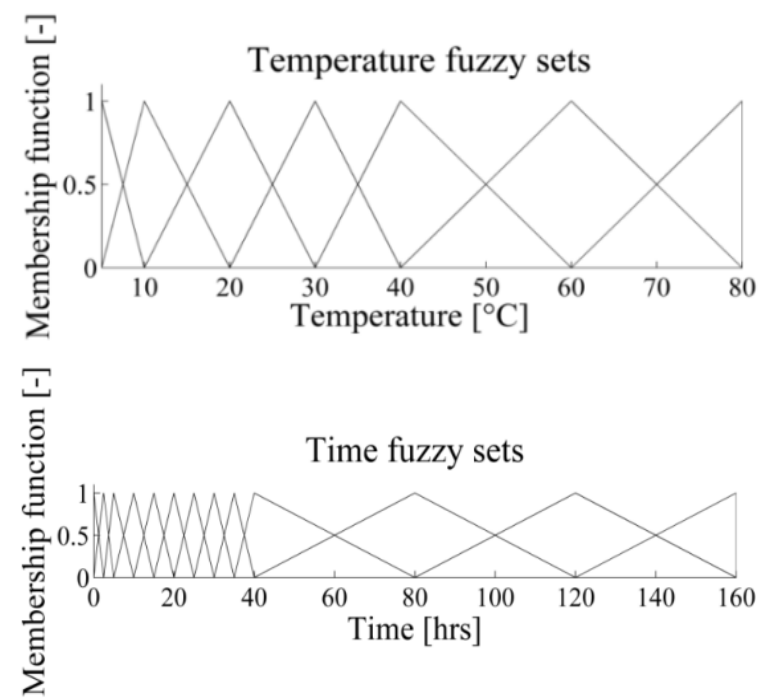

Fig. 5 Input fuzzy sets for temperature and time

The proposed fuzzy-logic-based model of hydration heat liberation takes into account the input variable of temperature and age of concrete (in terms of time), and the output variable of rate of hydration reaction. Fig. 5 shows the fuzzy set distribution over the universes of the input variables. The universe of the output variable is covered by two fuzzy sets, the 'zero rate' and the 'maximum instantaneous rate', which is derived from the experimental data on the hydration reaction rate at a given instant shown in Fig. 3.

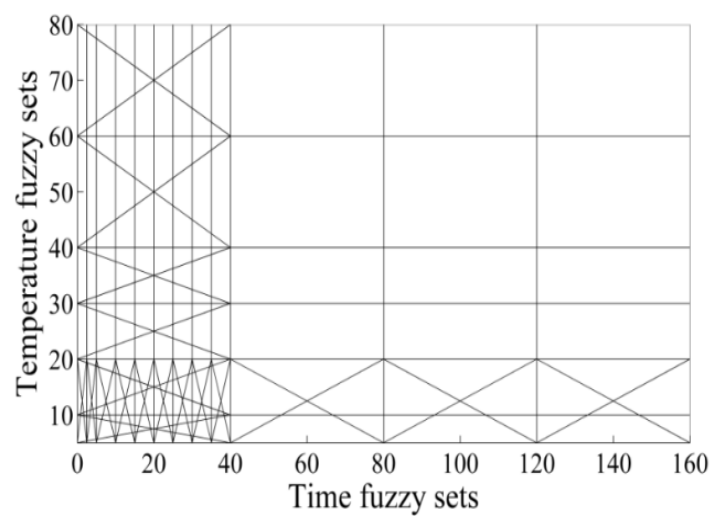

Fig. 6 Output fuzzy sets of hydration rate

The proposed model works at two stages divided by the $50 \%$ of the degree of hydration. In the first stage, the model decides the hydration rate with respect to the instantaneous temperature at material (or Gaussian) point and mathematically the procedure resembles the linear interpolation. Once the $50 \%$ of the degree of hydration is achieved, the model switches to the second stage, which describes the hydration reaction when controlled by diffusion. At this stage, the weighted average of the temperature history is considered instead of the instantaneous temperature and an additional fuzzy controller is activated, which ensures that the maximum possible amount of liberated heat is not exceeded. The reason is that, for example, when the temperature of concrete is very high at the beginning, the $50 \%$ of the total heat are liberated very rapidly, but then suddenly the temperature is reduced to about $10^{\circ} \mathrm{C}$, based on the curves in Fig. 3 the heat would exceed the possible range of the value attainable at the age of one week (168 hours). Therefore, in such cases the rate of hydration heat is reduced gradually so that it maximum heat at one week is not exceeded. It should be noted that the rate of hydration reaction at its deceleration (see Fig. 3) is much lower that at its high, which decides the increase of temperature of concrete to be taken into account during construction process. Therefore, introduction of the limiting controller is acceptable when compared with the advantage of constructing the proposed moment based on few hydration rate curves, which can be easily obtained from the standard calorimetry test.

The fuzzy controllers used at both the stages for selecting the instantaneous rate of hydration reaction are the standard Mamdani-type controllers which operate with 91 decisions ( 7 fuzzy sets for temperature and 13 fuzzy sets for age), which can be seen in Fig. 6. The fuzzy controller used for limiting the maximum liberated heat is also of the Mamdani type working with 8 decisions and the fuzzy sets used as input are defined on the universes of the actual age of concrete ( 2 fuzzy sets), the actual difference between instantaneous accumulated heat and the target heat at one week (2 fuzzy sets), and the actual rate of hydration reaction ( 2 fuzzy sets). The output is the corrected rate of hydration reaction.

\section{Third routine - risk of cracking}

The risk of possible cracking of early-age concrete considers the stresses caused by thermal expansion and subsequent contraction and shrinkage. The calculation of shrinkage stresses are based on the B3 model for shrinkage [3], which takes into account the curing method and its duration, the type of cement, the shape of section-section, the water content and the relative humidity. The result of the B3 model is in the form of a uniform distribution of strains, which after multiplication by the instantaneous modulus of elasticity gives the shrinkage-induced stress. The modulus of elasticity can be derived, e.g. from the degree of hydration. The thermal expansion and contraction strains are obtained by simple multiplication of the temperature differences with the expansion coefficient $\left(\alpha=0.000012 \mathrm{~K}^{-1}\right)$. With regard to the character of the stresses distribution, the cracks initiation can be expected at the edges of the analyzed section with their subsequent propagation toward the center part. The depth of the cracks can be evaluated based on the stress distribution. The instantaneous tensile strength also can be derived from the degree of hydration. 


\section{Discussion of results}

As an example, a wall section, which is 1 meter thick and 3 meters high and which is made of heavy concrete and ordinary Portland cement, is selected. The mix proportions and thermal properties are not given as this is only a general example of applicability of the proposed model. The geometry of this type of the problem can be seen in Fig. 4.

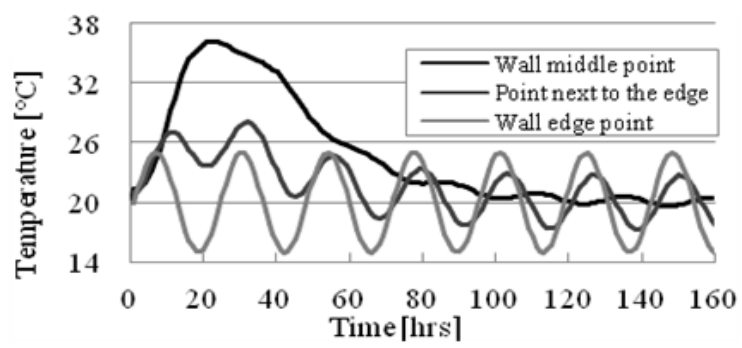

Fig. 7 Temperature evolution in nodes

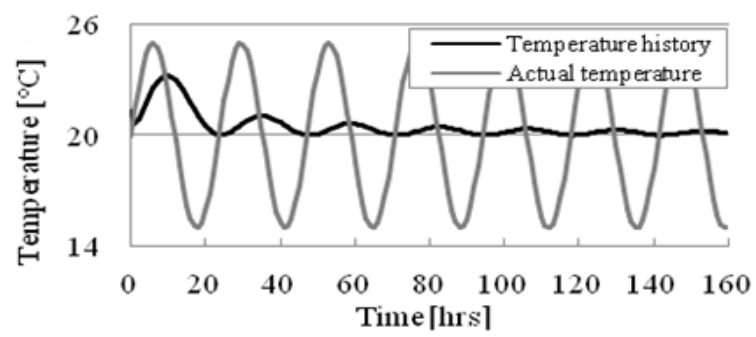

Fig. 8 Actual temperature and temperature history

The time step used in the thermal analysis is 1 hour. The outside temperature is defined by a sine function with the mean value of $20^{\circ} \mathrm{C}$ and the amplitude of $5^{\circ} \mathrm{C}$. In Fig. 7 and 8 it can be seen that the temperature at the age of 0 hours is $20^{\circ} \mathrm{C}$ and that the outside temperature, which is equal to the nodal value on the edge of the problem, starts increasing. This caused acceleration of hydration reaction in the surface layer of concrete, while concrete at the centre of the wall lacks in the rate. After about ten hours of age, the outside temperature starts decreasing, which has a positive effect on the concrete. On the other hand, temperature inside the wall continues increasing, when the increase is primarily governed by the hydration heat, which cannot escape from the concrete mass fast enough. The temperature distributions inside the concrete wall and on its surface are shown in Fig. 7 where it is also evident that the temperature inside the wall is higher on average that the surface temperature.

At the age of about 10 hours, the model of the hydration reaction switches from the kinetic energy control to the diffusion control and thus it starts following the

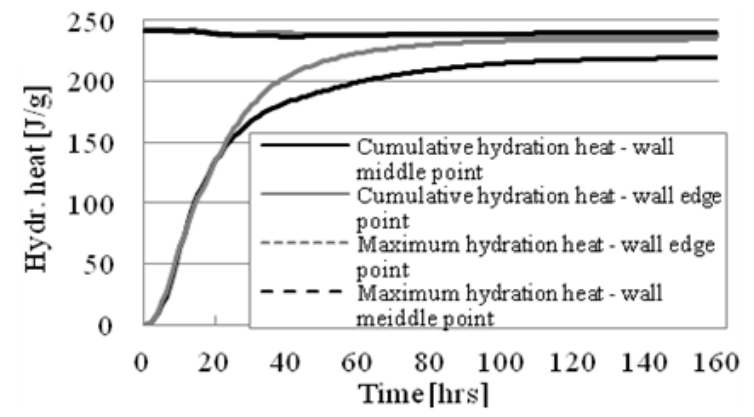

Fig. 9 Cumulative hydration heat weighted-average temperature history. The difference between the instantaneous and the weighted-average temperature is shown in Fig. 8.

Therefore, the hydration heat at the centre of the wall does not reach its possible maximum value by the age of 160 hours. On the contrary, the hydration heat reaches its maximum value by the age of 160 near the surface, as the temperature is more favourable for the hydration reaction during the whole 160 hours. The comparison of the cumulative hydration heat at the centre and the surface of the wall are shown in Fig. 9. The temperature history obtained from the simulation is shown along the thickness indicated in Fig. 10.

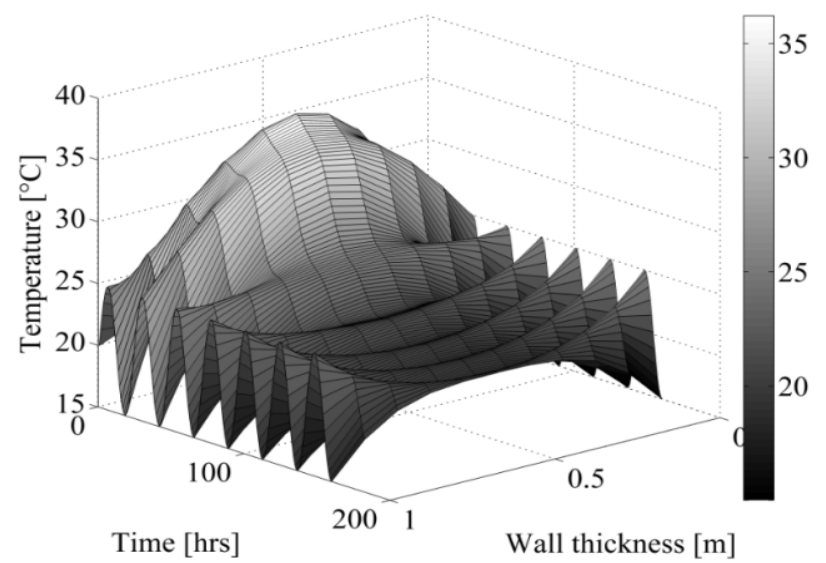

Fig. 10 Temperature distribution in cross-section

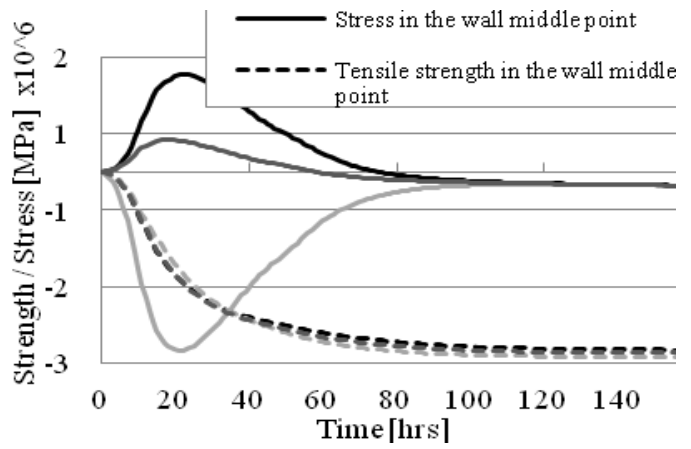

Fig. 11 Stress and strength development in section

Based on the distribution of temperature, the thermal strains are obtained. When combined with the shrinkage strains obtained from the B3 model [6] and multiplied by the instantaneous modulus of elasticity, the stress distribution obtained. The comparison of the stress distribution with the instantaneous tensile strength shows the possible locations of cracking. The stress and tensile strength development is shown in Fig. 11. This comparison also allows estimation of the crack depth, as can be seen in Fig. 12.

\section{Conclusion}

The main objective of this paper was to demonstrate the differences in the rate of hydration reaction due to different temperatures. Based on the higher or lower temperature values we can observe different trends in acceleration or deceleration of hydration reaction, and from the numerical analysis results, we can derive the actual strength of concrete. Hence, for the practice, it means reduction of technological breaks on construction site and 
also reduced costs. As an application, the risk of cracking in concrete caused by thermal expansion and shrinkage is estimated, which is essential in the case of massive concrete structures, which are the most jeopardized by the liberated hydration heat. Also, the results can be used as an input for other types of software for analyses of building structures which take into account the temperature effects on the early-age concrete.
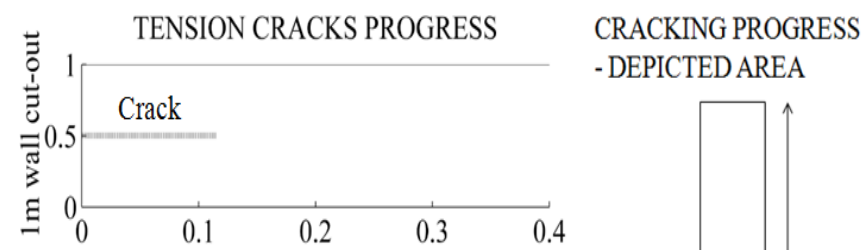

STRENGTH AND STRESSES DEVELOPMENT
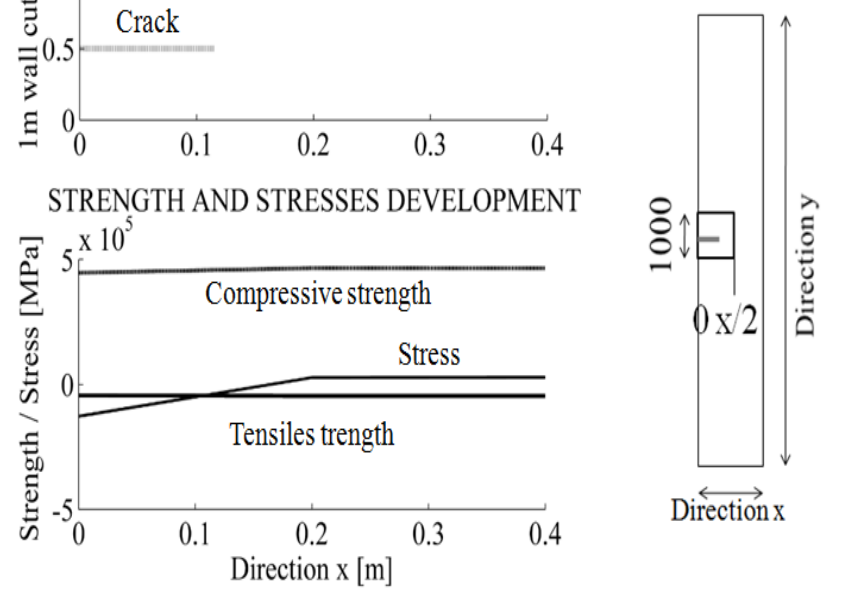

Fig. 12 Prediction of cracking progress and depth of crack

\section{Acknowledgement}

This work was supported by the Czech Science Foundation, project 103/08/1372, and by the Ministry of Education, Youth and Sports of the Czech Republic, project MSM6840770003, which are gratefully acknowledged.

\section{References}

1. Štemberk, P.; Kalafutová, P. 2008. Modeling very early age concrete under unaxial short-time and sustained loading, Mechanika 2(70): 16-21.

2. Kada-Benameur, H.; Wirquin, E.; Duthoit, B. 2000. Determination of apparent activation energy of concrete by isothermal kalorimetry, Cement and Concrete Research 30: 301-305.

3. Bažant, Z.P.; Baweja, S. 1995. Creep and shrinkage prediction model for analysis and design of concrete structures - model B3, Materials and structures 28: 357365.

4. Jakušovas, A.; Daunys, M. 2009. Investigation of low cycle fatigue crack opening by finite element method,
Mechanika 3(77): 13-17.

5. Stan, S.-D.; Bălan, R.; Mătieş, V.; Rad C. 2009. Kinematics and fuzzy control of ISOGLIDE3 medical parallel robot, Mechanika 1(75): 62-66.

6. Klir, G.; St. Clair, U. H.; Yuan, B. 1997. Fuzzy set theory: foundation and application. Upper Saddle River: Prentice-Hall.

7. Pokorná, N. 2010. Dissertation thesis: Definition of material models and engineering problems by fuzzylogic tools. Prague: CTU in Prague.

\section{P. Štemberk, A. Rainova}

\section{HIDRACIJOS IR PLYŠIU PLITIMO IMITAVIMAS ATSIŽVELGIANT I TEMPERATŪROS EFEKTĄ IR REMIANTIS FUZZY LOGIKOS TEORIJA}

R e z i u m è

Straipsnyje aprašoma temperatūros ir jos kitimo itaka ị hidratacijos šilumos sklaidą betono konstrukcijose ir temperatūros pasiskirstymui šviežiame betone. Pagrindinis šio darbo tikslas - nustatyti temperatūros ittaką betono hidratacijos procesui, hidratacijos greičio bei medžiagos stiprumo kaitą ir sukauptą hidratacijos šilumą. Remiantis analizès duomenimis, nustatyta, kaip betono konstrukcijos irimo pavojus priklauso nuo susitraukimo ir linijinès šilumos sklaidos, nustatytas plyšio gylis ir geometrija.

\section{P. Štemberk, A. Rainova}

\section{SIMULATION OF HYDRATION AND CRACKING PROPAGATION WITH TEMPERATURE EFFECT BAWSED ON FUZZY LOGIC THEORY}

\section{S u m m a r y}

This paper deals with the influence of temperature and temperature history on the development of hydration heat in concrete structures and on evaluation of temperature distribution in early-age concrete. The main objective of this work is estimation of temperature influence on hydration progress in concrete during hydration reaction, then the evaluation of hydration rate, cumulative hydration heat and evolution of actual material strength. Further, the risk of cracking in concrete structure due to shrinkage and linear thermal expansion is estimated and based on results of crack risk analysis, the depth and geometry of the crack is obtained.

Received February 08, 2011 Accepted June 30, 2011 